\title{
Really Complex Demonstratives: A Dilemma
}

\section{Ethan Nowak ${ }^{1}$ iD}

Received: 7 February 2019 / Accepted: 8 April 2020 / Published online: 20 May 2020

(c) The Author(s) 2020

\begin{abstract}
I have two aims for the present paper, one narrow and one broad. The narrow aim is to show that a class of data originally described by Lynsey Wolter (That's that; the semantics and pragmatics of demonstrative noun phrases, $\mathrm{PhD}$ thesis, University of California at Santa Cruz, 2006) empirically undermine the leading treatments of complex demonstratives that have been described in the literature. The broader aim of the paper is to show that Wolter demonstratives, as I will call the constructions I focus on, are a threat not just to existing treatments, but to any possible theory that retains the uncontroversial assumptions that relative clauses always form a constituent with the nouns they modify, and that semantic composition proceeds sequentially and locally, with the inputs to interpretation having the structure syntax tells us they do.
\end{abstract}

\section{Introduction}

English demonstratives occur in two basic syntactic configurations. In the philosophical literature, examples of the first sort, illustrated by (1), are commonly called 'simple demonstratives', while examples of the second sort, illustrated by (2), are called 'complex demonstratives':

(1) That is a chipper/shredder.

(2) That chipper/shredder is a Troy Bilt model.

Complex demonstratives, which will be the sole focus of our discussion here, can themselves be used in a tremendous variety of what appear to be importantly different ways. Nunberg (1993), for example, called attention to complex demonstratives that

Thanks to Vitaliy Dolgorukov, Peter Jenks, Petr Kusliy, Eliot Michaelson, Daniel Rothschild, Seth Yalcin, John MacFarlane, Ekaterina Vostrikhova, Sangceup Yune, José Zalabardo, and three anonymous referees for comments and discussion.

Ethan Nowak

ethan.nowak@kcl.ac.uk

1 King's College London, London, UK 
produce 'deferred reference' effects, as when someone points at an empty stall in a barn and says:

(3) That horse is out to pasture.

and to demonstratives given 'role' type interpretations:

(4) (pointing at the new Argentine Pope) What a departure! He's usually Italian.

(5) (pointing at a neighbor's disappointingly-small lunch portion) Oh, man, I'm sorry-that's usually much bigger!

Roberts (2002) provided a detailed treatment of the way complex demonstratives can be used in discourse anaphora, as when someone says of an unknown person about whom their interlocutor has just made an assertion:

(6) That guy doesn't sound very cool.

Lakoff (1974), Wolter (2006), Potts and Schwarz (2010), and many other authors have noticed that emotional shading can sometimes be used to license complex demonstratives where they would typically not be expected to be felicitous:

(7) That (darn) Donald Trump was up all night on Twitter again...'

(8) That (darn) author of Waverley - he turns up everywhere in philosophy, doesn't he?!

Although questions about what kinds of semantic and pragmatic factors contribute to the licensing and interpretation of these various demonstrative constructions are fascinating, and although a fully-developed positive theory of demonstratives will surely have to speak to them in detail, for present purposes, these issues can be set aside. My aim here is not to provide a theory of demonstratives, but to call attention to a particularly worrisome dilemma that complex demonstratives clearly pose, but which theorists have consistently overlooked for decades. To appreciate that dilemma, it will be enough to focus our attention on a single high-level distinction that has shaped most of the philosophical literature on demonstratives. That distinction separates deictic uses of complex demonstratives, as illustrated by (9), from non-deictic uses, as illustrated by $(10)^{1}$ :

(9) Stop that man with the chipper/shredder! (pointing at a man with a chipper/shredder)

(10) Every arborist recalls with some fondness that first chipper/shredder she practiced with.

\footnotetext{
${ }^{1}$ Non-deictic demonstratives, described by Stockwell et al. (1973) and investigated by Maclaran (1982) and Roberts (1987), were thrust into the philosophical foreground by King (2001). Philosophers sometimes complain that non-deictic demonstratives were invented by other philosophers, and that they are never used in real life. Attested uses are in fact widespread; here is a recent example from Joe Biden: "You didn't hear a single sentence in the last campaign about that guy working on an assembly line making $\$ 60,000$ ". The reference here is presumably to a type, and not an individual, but the point that the use parallels the use of the corresponding definite description stands.
} 
The key difference between (9) and (10) concerns the role played by the context of utterance. Many philosophers take there to be an intuitive sense in which the demonstrative from (9) requires supplementation from the context in order to determine a referent. $^{2}$ The demonstrative from (10), on the other hand, picks out whatever it does independently of the context of utterance.

Despite the tremendous variety of semantic positions that have been described in the literature on complex demonstratives, there are essentially just two ways in which philosophers have attempted to explain the fact that what appears to be the very same word, 'that', can be used to produce this pair of distinctive readings. ${ }^{3}$ Defenders of HOMOPHONY claim that appearances mislead. ${ }^{4}$ On their view, the reason 'that' from (9) requires contextual supplementation, while 'that' from (10) does not, is that the two are different words of the same syntactic category that happen to be homophonous. ${ }^{5}$ One is a genuinely demonstrative element, while the other is a phonetic variation on the ordinary definite determiner.

Defenders of HIDDEN ARGUMENTS, on the other hand, take the apparent facts at face value. ${ }^{6}$ On their view, there is a single lexical item, 'that', which appears in both (9) and (10). This item is semantically similar to 'the', except that it has an extra argument place. When a demonstrative is used deictically, the HIDDEN ARGUMENT theorist claims that this argument place is saturated by a covert property that somehow contributes an individual from the context. When a demonstrative is used non-deictically, the hidden argument place is saturated by semantically vacuous material, and the result is equivalent to a definite description.

Although the point has been made in several places, philosophers have been reluctant to acknowledge that a class of data originally described by Wolter (2006) fatally undermine both HOMOPHONY and HIDDEN ARGUMENTS. ${ }^{7}$ Both views predict that (11)

\footnotetext{
${ }^{2}$ It is not easy to precisely characterize this sense without wheeling in the fully-developed apparatus of one semantic theory or another. For a rough illustration, imagine a context in which many landscape professionals are making to leave. The gesture that accompanies (9) determines one from among them as the referent of the demonstrative. Or so the story typically goes.

3 This characterization is not entirely fair to authors working in the tradition of dynamic semantics. Roberts (2002, 2003), for example, takes data involving certain classes of non-deictic demonstratives seriously, but her position does not fall neatly into either of these categories. For present purposes, however, it is safe to treat Roberts' view as a cousin of HIDDEN ARGUMENTS; although they take a superficially different form, as I show in Sect. 5, both her view and others like it are subject to the same worries as the worries I raise here for HIDDEN ARGUMENTS.

4 Kaplan (1977), Davies (1982), Neale (1993), Dever (2001), Salmon (2002, 2006, 2008), Comorovski (2007), and Georgi (2012) argue that a semantics for deictic demonstratives should not be expected to also cover non-deictic data. Dever (2001) and Georgi (2012) explicitly defend HOMOPHONY, which is also implied by remarks from Kaplan (1977), Corrazza (2003), and Braun (2008).

5 An anonymous referee points out that this characterization obscures a distinction between homophony and polysemy. I agree that these positions ought to be distinguished, and that there may be philosophers who would prefer to endorse one or the other of them. The distinction, however, does not change the outcome of the argument I offer here, so for simplicity's sake I will group defenders of polysemous views under HOMOPHONY.

6 Compare King (1999, 2001, 2008) and Elbourne (2005).

7 Compare Wolter (2006, 2007, 2009), and Nowak (2019).
} 
should be felicitous and admit an interpretation on which it means exactly what (12) does: 8

(11) \#That current president of the United States is Donald Trump.

(12) The current president of the United States is Donald Trump.

(11) does not involve an acceptable non-deictic demonstrative, however, and neither HOMOPHONY nor HIDDEN ARGUMENTS has the resources to explain that fact. ${ }^{9}$

Instead of rehearsing existing arguments against specific theories, my aim in the present paper will be to show that Wolter demonstratives, as I will call constructions like the one from (11), are a threat to any possible semantic theory that retains the following pair of uncontroversial assumptions ${ }^{10}$ :

STANDARD SYNTAX Relative clauses always form a constituent with the nouns they modify.

LOCAL COMPOSITION Semantic composition proceeds sequentially and locally, and the inputs to interpretation have the structure syntax tells us they do.

I will say more about STANDARD SYNTAX and LOCAL COMPOSITION below; for now, the key point is that holding them means accepting that in a sentence like (11), the determiner 'that' takes 'current president of the United States' as a single property-denoting argument.

The argument for the claim that Wolter demonstratives result in a dilemma is straightforward. Although it sounds stilted, (13) clearly admits a felicitous interpretation on which it has the same truth conditions as (14):

(13) That guy who is currently president of the United States is Donald Trump.

(14) The guy who is currently president of the United States is Donald Trump.

Unless one of STANDARD SYNTAX or LOCAL COMPOSITION is wrong, though, there will be no way to semantically distinguish the infelicitous (11) from the felicitous (13). If STANDARD SYNTAX is right, there should be no substantial semantic difference between

\footnotetext{
${ }^{8}$ I use the hash sign throughout to indicate a string that is infelicitous on the relevant interpretation; for our purposes, that will almost always mean 'to indicate a demonstrative sentence that admits no non-deictic reading'.

${ }^{9}$ It is important to be clear that (11) is not ruled out by syntax or semantics tout court. If there were two current presidents of the United States, it seems like it might be possible to use (11) deictically to pick out the less-qualified member of the pair. For further discussion, see Sect. 4.

10 Thanks are due to an anonymous referee for suggesting the following clarification. By 'Wolter demonstrative', I mean an infelicitous complex demonstrative whose infelicity can be resolved merely by recasting the predicate from which the demonstrative is formed using a relative clause. For simplicity and consistency, I focus my attention here on strings on which a Wolter demonstrative occupies the subject position in a specificational copular clause; see Higgins (1979) and Mikkelsen (2005) for discussion. It is important to emphasize that the puzzling distribution of Wolter demonstratives is not a product of this construction. Compare:
}
A. The/\#that author of Waverley was born in Edinburgh.
B. The/\#that author of Waverley also wrote Ivanhoe.
C. Not everyone realizes that the/\#that author of Waverley also wrote Ivanhoe.
D. Let's all take a second and think about the/\#that author of Waverley. 
'president of the United States' and 'guy who is currently president of the United States'; both predicates pick out the same property. ${ }^{11}$ If LOCAL COMPOSITION is right, the determiner has no discrete access to the semantic values of the individual expressions that make up the complex demonstrative; the determiner in 'that $F$ ' takes $F$ as a single property-denoting argument.

If my arguments succeed, philosophers who aim to offer an analysis of complex demonstratives must face a difficult choice: either give up at least one of STANDARD SYNTAX or LOCAL COMPOSITION, or offer compelling reasons for ignoring the problematic data. Since, as I will show here, those data are robust in English and other languages, the latter option is unattractive. The result is a puzzle that has not, so far, been properly appreciated. ${ }^{12}$

\section{Homophony}

Most philosophers who explicitly engage with the issues raised by non-deictic demonstratives offer a version of HOMOPHONY. As the name suggests, purveyors of this theory use one lexical item to explain deictic demonstrative data, and another item to explain non-deictic data. Although in principle it would be possible to construct HOMOPHONY theories out of a wide variety of different semantic components, the standard implementation involves claiming that deictic demonstratives are formed from a directly-referential version of the word 'that', while non-deictic demonstratives are formed from a homophone which means what 'the' does. ${ }^{13}$

According to HOMOPHONY, that is, what appears to be a single determiner, 'that', is really two distinct words:

(15) $\llbracket$ that $_{1} \boldsymbol{F} \rrbracket^{c, w}=$ the $F$ intended / ostended / etc. by the speaker of $c$

$$
\llbracket \text { that }_{2} \boldsymbol{F} \rrbracket^{c, w}=\llbracket \text { the } \boldsymbol{F} \rrbracket^{c, w}
$$

If someone points towards a chipper/shredder and says:

(17) That piece of equipment is just gorgeous.

a typical HOMOPHONY theorist will analyze the demonstrative using some precisification of the following template:

\footnotetext{
${ }^{11}$ Modulo an irrelevant difference introduced by the gender features associated with 'guy'. I use 'guy' over 'person' in the example to preserve consistency in the register.

12 Wolter (2006) herself explains these data by offering an alternative structural analysis of relative clauses, which I follow in Nowak (2019).

13 Dever (2001) explicitly defends this treatment, which, as noted earlier, is also suggested by discussion from Kaplan (1977), Corrazza (2003), and Braun (2008). In my mind, the most natural reading of Georgi (2012) also involves a pair of lexical items, although an anonymous referee points out that it is possible to read Georgi's remarks about how "the rules governing the use of demonstratives in English distinguish between referential and nonreferential uses" as leaving open the possibility of a polysemous treatment, i.e., a treatment that involves just one lexical item that encodes two related, but distinct meanings. In any case, since Georgi is manifestly committed to the idea that demonstratives are interpreted by means of two distinct principles, one that produces directly referential readings, and another that produces readings on which they are equivalent to definite descriptions, the shape of the dialectic, for present purposes, is unaffected by this distinction.
} 
(18) $\llbracket$ that $_{1}$ piece of equipment $\rrbracket^{c, w}=$ the piece of equipment ostended / intended / etc. by the speaker in $c$

On this treatment, the extension of the expression 'that piece of equipment', as used in the context described and evaluated at any world, is the piece of equipment ostended (or intended, or whatever) by the speaker of the context. So far, so familiar.

If, on the other hand, the owner of a new Troy Bilt concession should say:

(19) That first customer to walk through the door with a damaged unit will quickly see that there's a new level of service in town.

a typical HOMOPHONY theorist will analyze the demonstrative as per:

$\llbracket$ that $_{2}$ first customer to walk through the door.... $\rrbracket^{c, w}$ $=$

【the first customer to walk through the door... $\rrbracket^{c, w}$

Here there is no mystery about how the complex demonstrative comes to be interpreted like a definite description; the determiner from which the demonstrative is formed is semantically indiscernible from the definite article. A Russellian HOMOPноnY theorist will say that the complex demonstrative picks out a function from properties to truth values, while a Fregean will say that with regard to a circumstance of evaluation, it picks out whoever the first customer in that circumstance to come through the door with a malfunctioning piece of machinery is.

HOMOPHONY makes the right intuitive predictions about the cases that philosophers typically attend to, like the cases just cited. Sentences formed using Wolter demonstratives, however, clearly reveal that existing implementations of HOMOРнONY are empirically inadequate. Although (11) does not admit a non-deictic interpretation, replacing 'that' with 'the' results in a perfectly natural string:

(11) \#That current president of the United States is Donald Trump.

(12) The current president of the United States is Donald Trump.

This means that the version of 'that' which HOMOPHONY depends on to explain nondeictic demonstratives cannot simply be a phonetic variation on the word 'the'

At first glance, this might appear to be a wrinkle, instead of a fatal problem. A friend of HOMOPHONY might accept the Wolter demonstrative data, but take them to suggest an incremental modification of her theory, as opposed to a wholesale rejection. Instead of identifying 'that 2 ' with 'the', she might take Wolter demonstratives to show that 'that ${ }_{2}$ ' is broadly semantically similar to 'the', although not indiscernible. 'That ${ }_{2}$, the thought might go, involves some kind of complicated structural licensing condition, or involves different presuppositions, or something along these lines.

There are two things to notice here. First, no defender of HOMOPHONY has acknowledged this difficulty, let alone offered a theory that attempts to answer it. Second, as we shall see, unless we are willing to sacrifice one or the other of our pair of widely held theses about the syntax of relative clauses, and about the relationship between syntax and semantics, no possible modification of HOMOPHONY will be successful. The problem, in other words, is not just that no one has offered an empirically-viable proposal for 'that 2 ', it is that no such proposal could possibly be given without rejecting 
at least one member of a pair of theses that linguists and philosophers overwhelmingly want to keep.

\section{Hidden Arguments}

Apart from HOMOPHONY, the most prominent alternative approach to data involving non-deictic demonstratives involves the idea that all complex demonstratives share a semantic structure that makes them essentially a special kind of definite description ${ }^{14}$ :

(21) that $F=$ the $x:[F(x) \& G(x)]$

On this view, the primary difference between 'that' and 'the' is that 'that' involves an additional (covert) argument place. King (2001) defends a Russellian version of HIDDEN ARGUMENTS on which 'that' combines with two property-denoting expression to make a generalized quantifier, while Elbourne (2005) develops a Fregean version, on which 'that' takes two property-denoting expressions and returns the unique individual that satisfies both properties.

When a demonstrative is used deictically, both authors say that the $G$ argument place is saturated by a hidden argument that corresponds to an identificational property, i.e., a property like 'being identical to Margueritte'. For King (2001), which property that is is determined by the speaker's referential intentions, while for Elbourne (2005), the hidden argument place is occupied by a variable over identificational properties, the value of which is set by a contextually-determined assignment function. On either version of the theory, if someone standing in Store Street in London points towards Senate House and says:

(22) That building is alleged to have been among the inspirations for Orwell's Ministry of Truth.

her demonstrative will be represented along the following lines:

(23) the $x$ : [building $(x) \&$ identical-to-Senate-House $(x)$ ]

The object that is both a building and that is identical to Senate House, of course, is Senate House, so HIDDEN ARGUMENTS makes the right predictions about standard deictic cases.

The major selling point of HIDDEN ARGUMENTS is that the same basic semantic structure that is used to explain deictic uses of complex demonstratives can be applied in the case of non-deictic uses, as well. When a demonstrative is used non-deictically, King claims that the $G$ argument place is saturated by a trivial property, like the property of being self-identical. Elbourne does not explicitly take up the case of non-deictic demonstratives, but his semantics can be naturally extended to cover non-deictic uses by allowing 'that' to take a trivial second argument. ${ }^{15}$

On either implementation, the demonstrative from a sentence like:

\footnotetext{
14 I offer this simplified presentation for ease of exposition. An anonymous referee points out that it would be more precise to characterize King's position by saying that the determiner 'that', with regard to a context, has the semantic type of a restricted existential quantifier. This formulation, however, does not change the upshot where the present arguments are concerned.

15 Elbourne relies on this technique frequently to explain other constructions.
} 
(24) That first guy that Trump made attorney general was previously a senator.

is represented as per:

(25) the $x$ : [first-guy-that-Trump-made-AG $(x) \&$ self-identical $(x)$ ]

Every object is self-identical, so the second argument adds nothing substantial to the derivation for (25). This means that the demonstrative from (24) will be interpreted as though it were equivalent to the definite description:

(26) the first guy that Trump made attorney general

As was the case with HOMOPHONY, it is easy to see that HIDDEN ARGUMENTs has no problem generating the desired readings for sentences like (24). The only object that is a guy whom Trump made attorney general (at least at the time of this writing) is Jeff Sessions, which is the extension we expect for the non-deictic demonstrative 'that guy that Trump made attorney general'. As was the case with HOMOPHONY, however, HIDDEN ARGUMENTS predicts that non-deictic demonstratives should be available wherever definite descriptions are. Consider (11) and (12) again:

(11) \#That current president of the United States is Donald Trump.

(12) The current president of the United States is Donald Trump.

If HIDDEN ARGUMENTS were right, we would expect (11) to admit a felicitous reading on which it means exactly what (12) means. We would expect, that is, to be able to analyze the demonstrative as per:

(27) the $x$ : [current-US-president $(x) \&$ self-identical $(x)$ ]

Of course, the unique object that is the current US president and that is self-identical is Trump. So HIDDEN ARGUMENTS would make Trump the extension of the demonstrative from (11). But the demonstrative from (11) is defective; it does not pick out Trump, or anyone else.

Just like HOMOPHONY, HIDDEN ARGUMENTS would make a non-deictic interpretation available for a demonstrative wherever a definite description can be used. But Wolter demonstratives show that the two classes of expression are not interchangeable. They show, in other words, that HIDDEN ARGUMENTS is wrong: the availability of non-deictic interpretations for demonstratives cannot be explained by simply allowing 'that' to take a trivial second argument.

\section{False Hope?}

As we have just seen, the empirical problem with HOMOPHONY and HIDDEN ARGUMENTS is that both theories overgenerate. By identifying 'that 2 ' with 'the', HOMOPHONY leaves its purveyor no way of distinguishing felicitous non-deictic demonstratives from infelicitous instances. Because her theory allows the second argument of 'that' to be a trivial one, the defender of HIDDEN ARGUMENTS has no way to prevent the determiner from taking any property-denoting argument and returning its sole satisfier (if such there be). 
Of course, overgeneration by itself does not constitute a devastating objection to a theory. All semantic theories are susceptible to counterexamples, and it would be prima facie plausible to think that someone could respond to the difficulty posed by Wolter demonstratives not by rejecting HOMOPHONY Or HIDDEN ARGUMENTS, but by working out a more sophisticated version of one or the other, a version that would continue to generate non-deictic interpretations while offering a way of filtering out the unwanted ones.

My aim here is to show that there is no way of pulling off this trick, or at least, no way of doing so without giving up a thesis that few philosophers or linguists will be inclined to give up. The problem is not just that both theories overgenerate-it is that so would any retooled version of one or the other, or indeed, any other possible semantic proposal. The argument I will offer to support this pessimistic claim is inspired by the method of proof by induction. I start by sketching an intuitively-appealing response to the overgeneration problem on behalf of HOMOPHONY and HIDDEN ARGUMENTS. Then I show how the response is incompatible with standard assumptions about the syntactic structure of relative clauses and about semantic composition. The problem I will describe is a perfectly general one; it undermines the particular response I offer, but it will undermine any other attempt at responding to the overgeneralization problem, too. I conclude that Wolter demonstratives force tough choices on philosophers, choices they have not thus far reckoned with.

To begin, consider a typical sentence formed with a Wolter demonstrative:

\section{(11) \#That current president of the United States is Donald Trump.}

Beyond the mere fact of infelicity, sentences like (11) elicit an intuition about the source of the problem. A natural response to someone who utters (11) is: 'What do you mean 'that' current president of the United States? There's just one current president!'16

To the extent that you are tempted to offer this response, you may be tempted to wonder whether the problem with (11) has something to do with the predicate from which it is formed, 'current president of the United States'. Interestingly, that predicate has a property that not every predicate does - at least with regard to contexts drawn from the actual world and history so far, if it picks out anything, it picks out just one thing. Could it be that non-deictic demonstratives involve some kind of antiuniqueness requirement that is incompatible with this property? At first glance, the idea that demonstratives involve some kind of anti-uniqueness requirement seems empirically well-supported ${ }^{17}$ :

(28) a. \#That inventor of bifocals was Benjamin Franklin.

b. The inventor of bifocals was Benjamin Franklin.

a. \#That FBI chief is Andrew McCabe.

\footnotetext{
16 If you do not share this intuition, or are disinclined to place any significant weight on it, no matter. The argument that follows takes the intuition as an evocative starting point, not a theoretical foundation.

17 To reprise a point I made in note 10 in response to an anonymous referee, notice that this intuition about anti-uniqueness does not crucially involve copular clauses:

E. The/\#that inventor of bifocals usually rode a bicycle to work.
} 
b. The FBI chief is Andrew McCabe.

(30) a. \#That highest-earning BBC presenter is Chris Evans.

b. The highest-earning BBC presenter is Chris Evans.

(31) a. \#That tallest mountain in North America is Denali.

b. The tallest mountain in North America is Denali.

The infelicitous a-versions of (28)-(31) are all constructed from predicates that connote uniqueness; unless we are willing to be permissive with regard to our understanding of the concepts involved, only one person can be the chief of an organization, be the inventor of something, or be the highest-paid or tallest object in a class.

Could the solution to the problem of Wolter demonstratives be as simple as saying that complex demonstratives cannot be formed using predicates that themselves pick out just a single individual? Although many commentators have informally suggested versions of this response in private conversation, a moment's reflection should reveal it to be a red herring - the whole point of a theory of non-deictic demonstratives is to show how they come to be interpreted like definite descriptions (expressions that are classically assumed to require uniqueness). ${ }^{18}$

In fact, the outlines of the real challenge Wolter demonstratives pose only begins to take shape when we notice that all of the bad sentences from (29)-(31) can be made acceptable by refashioning the demonstratives from which they are formed using relative clauses:

(32) That person who invented bifocals was Benjamin Franklin.

(33) That person who is chief of the FBI is Andrew McCabe.

(34) That BBC presenter who is highest-paid is Chris Evans.

(35) That North American mountain that is taller than all the rest is Denali.

Only one person invented bifocals: Benjamin Franklin. Only one person is chief of the FBI: Andrew McCabe. And so on. Since (32)-(35) are felicitous when the demonstratives therein are interpreted non-deictically, our puzzle evolves. Where we started out with one question: 'What rules out Wolter demonstratives?' we now face another: 'What is it that makes Wolter demonstratives bad, but relative-clause permutations on them good?'

Although these data show that we cannot explain the infelicity of the bad Wolter data by simply saying demonstratives involve a requirement of anti-uniqueness, in their own way, they reinforce the thought that there is something right about that idea. A theorist confronted with the contrast in these data, i.e., with the contrast between

\footnotetext{
18 Whether implemented in the semantics, or offered as a pragmatic explanation, if STANDARD SYNTAX and LOCAL COMPOSITION are true, the idea that complex demonstratives cannot be formed from predicates that pick out a singleton is manifestly empirically inadequate. The famous 'quantifying-in' sentence from King (2001) shows this: Every professor $_{\mathrm{i}}$ cherishes that first paper she $_{\mathrm{i}}$ published. The assignment-sensitive constituent that first paper she $_{\mathrm{i}}$ published picks out a singleton, when interpreted, as it must be in order to determine a truth condition, with regard to a variable assignment. King's so called 'no demonstration, no speaker reference' examples make the same point: That person who wins the most votes in this election will be president. Obviously, there is at most one person who wins the most votes. Obviously, this sentence has a felicitous non-deictic reading.
} 
the set (28a)-(31b) and the set (32)-(35), would be forgiven for noticing that the predicates that are modified by the relative clauses in (32)-(35) are all predicates that have multiple satisfiers. While there can be just one president of the United States, there are many guys (one of whom is president). While there can be just one tallest mountain in North America, there are many mountains on that continent (one of which is taller than the rest).

These reflections suggest a possible solution to the problem posed by Wolter demonstratives. At a high level of generality, it seems like we could handle the data if we said that complex demonstratives somehow involve requirements of both uniqueness and anti-uniqueness. Like a definite description, a singular complex demonstrative designates the unique satisfier of some property. Unlike a definite description, that property has to be composed from two others that stand in a certain complex relation; one has to be satisfied by multiple objects, and the other has to be instantiated by just one of those objects. So, in the case of (32), the object that satisfies "who invented bifocals' is picked from among the objects that satisfy 'person'. In the case of (34), the object that satisfies 'who is highest-paid' is picked from among the objects that satisfy 'BBC presenter'. And so on.

In addition to the fact that this generalization would allow us a way of distinguishing between felicitous and infelicitous non-deictic demonstratives, it seems to fit with some natural thoughts about the role demonstratives play in our communicative lives. One of the central uses of deictic demonstratives is to pick a single object out from a set of alternatives that is given by context. If someone asks: 'Which $F$ ? we frequently answer: 'That one', pointing at one from among the candidates. This idea comes out in the work of many philosophers. Compare, for example, a formulation from Reimer (1991):

A not implausible view about the reference of expressions of the form 'that $F$ ', is that such expressions refer to $F$ 's which have somehow been 'discriminated' from all other $F$ 's. After all, when a speaker uses an expression of the form 'that $F$ to refer to a particular $F$, there is an implication to the effect that the intended $F$ is somehow 'discriminated' with respect to all other $F$ 's. (pg. 178)

On one way of understanding the programmatic solution offered just above, the key move is to claim that a relative clause can perform the kind of semantic work that is typically done by pointing gestures. ${ }^{19}$ According to Reimer, a pointing gesture can discriminate one $F$ with regard to all others. If our story is correct, a relative clause can be used to accomplish the same purpose. The friend of номорноNy could use this idea to amend her theory; instead of saying 'that ${ }_{2}$ ' is semantically indiscernible from 'the', she could say that it works broadly like 'the' does, but that it includes a 'discrimination' requirement, which can be met by a relative clause. The idea should be even more intriguing to the friend of HIDDEN ARGUMENTS, as it emphasizes the sense in which deictic and non-deictic demonstratives are two faces of the same semantic coin.

19 An anonymous referee points out that this treatment echoes an idea from Vendler (1967) and Cooper (1975), to the effect that restrictive relative clauses can sometimes occupy the position of a covert (contextually-saturated) restrictor variable. 
Of course, significant work would have to be done to turn the idea that demonstratives require discrimination into a theory about complex demonstratives. Something would have to be said about why relational genitives like 'president of the United States' fail to meet the criterion proposed, the original empirical generalization would have to be checked against a much wider range of data, including data of all the sort mentioned at the beginning of this paper, and the details would have to be made precise in a compositionally-plausible way. ${ }^{20}$

Unfortunately, standard assumptions about the syntax of relative clauses and about the relationship between syntax and semantics make the latter task impossible. Unless we are willing to jettison some of those assumptions, this means there is little point in pursuing either of the former two.

Although there is significant debate among linguists about the internal structure of relative clause and about what kinds of operations are involved in generating one, essentially no one doubts that relative clauses form constituents with the nouns they modify, resulting in syntactic structures like the following ${ }^{21}$ :

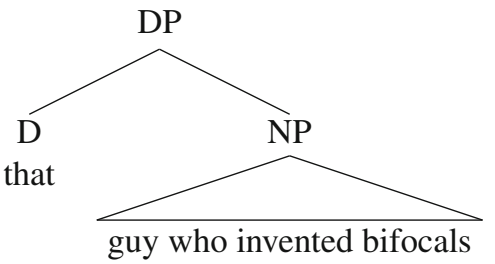

By the same token, essentially no one doubts that the inputs to the compositional semantic process used to derive a semantic value for a complex demonstrative like 'that guy who invented bifocals' have the structure shown in (36). ${ }^{22}$ On standard thinking, which according to Heim and Kratzer (1998) is due to Quine (1960), relative clauses essentially serve to turn a sentence into a predicate, which then combines with the noun the clause modifies to provide a single property-type argument for the determiner:

[The] particular genius of the relative clause is that it creates from a sentence '...x...' a complex adjective summing up what that sentence says about $x$...

...A fruitful basis for singular descriptions is the general term of the form of a relative clause; thence 'the car which I bought from you'. Let us build this example from its elements. We have a triadic relative term 'bought from', which, applied predicatively to the singular terms 'I', ' $x$ (say), and 'you', gives a sentence form 'I bought $x$ from you'. Putting the relative pronoun for the ' $x$ ' here and

\footnotetext{
20 The issue with relational genitives can be appreciated by noticing that the guy who is currently president of the US satisfies both 'guy' and 'current president of the US'. He satisfies 'president' but not 'of the US', which is not a property of individuals, or at least, not the one that is at issue here. In Nowak (2019), I attempt to provide a theory of the sort described here, but crucially, the result dispenses with STANDARD SYNTAX.

21 For three prominent contemporary treatments of relative clause, see Kayne (1994), Heim and Kratzer (1998), and Sauerland (2003).

22 Some readers will wonder: if this is the structure for relative clause, where do HIDDEN ARGUMENT theorists put their trivial properties? On Elbourne's view, the determiner itself is accompanied by an index whose value can be trivial. King's semantic treatment is not formulated at a level of resolution that would settle this question.
} 
permuting, we get the relative clause 'which I bought from you'. This clause is a general term, adjectival in status. Combining it attributively with the general term 'car', we get the general term 'car which I bought from you'; and then 'the' yields the singular term. (Quine 1960, pp. 110-111)

In other words, according to the consensus view, 'guy' and 'who invented bifocals' combine to yield a single constituent that picks out the property had by all and only people who invented bifocals. While the property in question is derived from properties that meet the constraints we relied on earlier to distinguish licit from illicit non-deictic demonstratives, that information is not represented at a level that is accessible to the determiner. From the perspective of the determiner, 'guy who invented bifocals' is a semantically-undifferentiated monolith. This means that our candidate solution cannot be implemented in a compositionally-plausible way that is consistent with state-ofthe-art thinking about relative clauses.

To appreciate the same problem in a different light, compare the uncontroversial structure of the Wolter demonstrative '*that inventor of bifocals':

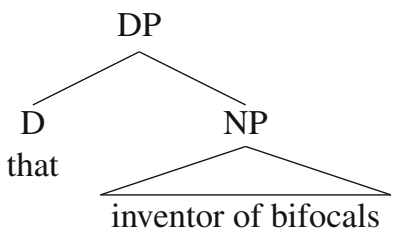

As was the case with the relative clause variation, this structure allows us to ignore the question of what goes on syntactically or semantically inside of NP. For our purposes, what is important is that the demonstrative determiner takes the expression 'inventor of bifocals' as a single argument. That argument, of course, contributes the property had by all and only inventors of bifocals. But this means that as far as the determiner is concerned, there is no difference between (36) and (37)! Whatever differences there might have been in the internal structure of the relative clause or the genitive construction are obliterated by semantic composition-by the time they make it to the point of combining with the determiner, both constituents have the same extensional semantic values. ${ }^{23}$

\section{The Grip of the Dilemma}

Let us take stock. We started with a puzzle: what mechanism makes a non-deictic reading available for the demonstrative from (10), but not for (11)?

(10) Every arborist recalls with some fondness that first chipper/shredder she practiced with.

\footnotetext{
23 In principle, there is room here to attempt an intensional or even hyper-intensional defense of our provisional solution. Someone might say that 'guy who invented bifocals' is intensionally or hyper-intensionally different from 'inventor of bifocals' and try to exploit that fact in reconstructing a solution. This seems like an implausible reach, but it cannot be ruled out a priori. Note, however, that 'inventor who invented bifocals' or 'person who invented bifocals' could be used to generate the same problem; it is hard to see how an intensional dodge would work for those predicates.
} 


\section{(11) \#That current president of the United States is Donald Trump.}

We had a suspicion that maybe the difference had something to do with the fact that the expression 'current president of the United States' somehow connotes uniqueness. That seemed like a promising lead, as it seemed like it might help with a further complication we noticed along the way, i.e., with the fact that (11) can be repaired by replacing the predicate from which it is formed with a relative clause construction:

(13) That guy who is currently president of the United States is Donald Trump.

Now we have seen reasons for thinking that our solution was a chimera. Syntax tells us that in relative clause constructions, like 'guy who is currently president of the United States', the demonstrative takes the noun and the relative clause that modifies it as a single argument. If we maintain that the inputs to semantic interpretation retain the argument structure syntax provides, this means that the noun and the relative clause together pick out a single property. But that property is semantically indiscernible from the one contributed by 'current president of the United States' ${ }^{24}$ This means we cannot appeal to the fact that 'guy' is satisfied by multiple objects in trying to explain why the relative clause constructions license non-deictic interpretations of demonstratives - the determiner simply does not have any chance to interact with 'guy' as an independent constituent.

Although the discussion here has unfolded against the backdrop of a particular proposal involving requirements on the cardinality of the arguments to 'that', it is crucial to note that the negative conclusion is a totally general one. The problem is not just that there is no way for the determiner to independently query the cardinality of the components that make up its argument. It is that there is no way for the determiner to independently query any of the semantic features of those components. Whatever you think the characteristic features of the constituents that compose to form a single argument to 'that' are, they will not themselves accessible to the determiner. So, it does not matter at all what your particular line on Wolter demonstratives is. Unless you give up one of the theses we began with, there is no way to make sense of the data:

STANDARD SYNTAX Relative clauses always form a constituent with the nouns they modify.

LOCAL COMPOSITION Semantic composition proceeds sequentially and locally, and the inputs to interpretation have the structure syntax tells us they do.

I recognize that this may sound to some readers like an overly precipitous conclusion. The conditions under which complex demonstratives are licensed, especially in nondeictic cases, appear to be extremely complicated. So, some will wonder, how can we be sure that the dilemma I describe will survive future discoveries about the factors that play a role in in our felicity judgments? In the remainder of this section, I answer that question by considering two hypothetical ways in which someone might try to dodge my negative conclusion.

The first, due to an anonymous referee, takes as a starting point the observation that parenthetical material produced by a speaker uttering a demonstrative can license

\footnotetext{
24 Or, as per note 11 , if there is a difference, it concerns only gender presuppositions that accompany 'guy'. It is not easy to see how such information would help in solving our problem.
} 
complex demonstratives that would otherwise be infelicitous. So, for example, the infelicitous demonstrative from (38) can be repaired by adding the parentheses from (39):

(38) \#That senior United States Senator from Massachusetts is a female candidate.

(39) That senior United States Senator from Massachusetts (Elizabeth something) is a female candidate (which I support).

Clearly, if (39) is a felicitous string, that fact demands explanation, since the same demonstrative shorn of the parenthetical would be ruled out. In order to provide an explanation, we will presumably have to tell a story that explains how the parenthetical material might interact semantically with the demonstrative. On the face of things, this seems likely to involve a substantial challenge-while there has been a lot of discussion about how best to represent non-restrictive relative clauses and appositive material that functions broadly like the referee's parentheticals, ${ }^{25} \mathrm{I}$ am not aware of any work that would treat parenthetical observations like the ones that occur in (39) as part of the syntactic projection of the demonstrative expression, or indeed, even as part of the sentence the demonstrative occurs in. ${ }^{26}$

Nevertheless, I certainly would not want to claim that this challenge cannot be met, or to rule out any particular strategy for meeting it. Indeed, I can imagine many ways a story might go-we might think the complex demonstrative involves a hidden argument place and the parenthetical provides a crucial extra-syntactic hint about the value of the argument in question. Or there might be no hidden structure in the demonstrative projection, but the demonstrative might be semantically incomplete in some way, with the parenthetical serving to reveal the required completion. Perhaps more radically, as an anonymous referee suggests, if we are willing to accept that the question of whether a certain non-deictic demonstrative construction is felicitous or not requires looking outside of the demonstrative construction itself, we might wonder whether some of the patterns in the data involving demonstratives might be due to differences not in the predicates the demonstratives are formed from, but in the matrix predicates from the sentences the demonstratives occur in.

For my purposes, what is important is that any way of telling any one of these stories will involve either revising the standard picture of the syntax of relative clause or accepting a form of semantic action at a distance. No amount of additional data we might gather about the circumstances in which complex demonstratives can be formed using predicates that denote a singleton will change the fact that relative clause constructions that by everyone's lights should have the same semantic values as nonrelative clause involving variations on them are acceptable, while the variations are not. Regardless of how the parenthetical brings about the licensing of the demonstrative from (39), that is, it is clear that (38) is infelicitous. But if STANDARD SYNTAX and LOCAL COMPOSITION are true, the demonstrative from (38) should be semantically indiscernible from the demonstrative from the following:

\footnotetext{
25 For an excellent survey, see de Vries (2006).

26 My own suspicion is that insofar as (39) sounds acceptable to some listeners, this is due to the fact that our linguistic judgments are not really precise enough to tell us which of two sentences that are interleaved during the production of (39) is the one we are responding to. (i.e., the bad *That senior US Senator from MA is a female candidate and the good Elizabeth something is a female candidate, which I support).
} 
(40) That more senior member of the Massachusetts delegation to the United States Senate is a female candidate.

In other words, regardless of what we end up saying about the factors that might render 'senior US senator from Massachusetts' acceptable in a non-deictic demonstrative, we have to face the fact that the standard picture of relative clause provides no way of reading those factors into "more senior member of the Massachusetts delegation to the United States Senate'.

Consider the hypothetical theories I mentioned just before. Suppose senior US senator from Massachusetts is bad on its own, but acceptable with a parenthesis because on its own the demonstrative determiner is missing an argument, and with the parenthesis, the slot in question is filled. That might be an empirically acceptable way of explaining the putative fact that (39) is felicitous, but how do we extend this theory so that it explains the fact that relative clause constructions without parentheses are fine? The natural thing to do here would be to try and tell a story on which the relative clause can somehow do the work the parenthesis does. But, on the standard syntactic picture of relative clause, there will be no way to pull this off! Again, the problem is precisely that the standard syntactic picture 'flattens' the relative clause, so that it ends up looking, from the perspective of the determiner, exactly the same as the non-relative construction without the parenthesis.

When discussing the problem Wolter demonstratives pose with philosophers, I have often encountered a different suggestion, which is that finding a solution might require giving up the so-called 'static' semantic framework I have described so far, in favor of a dynamic semantic theory of the sort introduced by Karttunen (1976) and Heim (1982). ${ }^{27}$ Indeed, it has often been suggested that the specific system described by Roberts (2002) might already fit the bill, since that system was explicitly designed to deal with demonstrative constructions that do not involve pointing at a determinate object from the context.

As readers will recall, in a dynamic semantic framework, the semantic value of an expression is modeled not as an extension to be fixed with regard to a set of points, but in terms of its contribution to what is called the 'context change potential' of the sentences in which it occurs. Dynamic contexts are typically treated not as places in space-time where a speech act might occur, or as a set of indices designed to provide an abstract representation of such, but as a body of information, modeled as a pair of a satisfaction set (a set of pairs of a world and a variable assignment) and a domain (a set of numerals corresponding to possible variable indices). The world/assignment pairs that make up the satisfaction set represent the live informational possibilities at a state in a conversation, while the domain organizes that information, as it were, by providing a register to track the discourse referents that have been previously introduced. The context change potential of a sentence, on this picture, is the mapping it realizes from contexts into contexts; in other words, the semantic value of a sentence is a function from pairs of a satisfaction set and a domain into pairs of a satisfaction set and a domain.

\footnotetext{
27 For an extended presentation of dynamic semantics generally, and in particular, of the system described by Heim (1982), compare Yalcin (2012, 2013). For an especially clear presentation and explanation of a contemporary system based on Heim's, compare Rothschild (2018).
} 
While the comparative advantages of dynamic semantic systems are well known, particularly where cross-sentential anaphora are concerned, ${ }^{28}$ switching from a static framework to a dynamic one does nothing to solve our problem. Regardless of whether we think that the distinctive features of definiteness are best thought of in terms of uniqueness or familiarity, or how we cash out the notion of familiarity, or what exactly we think a discourse referent is, at the end of the day, the basic role of the predicative material associated with a definite expression is to do two things. First, that material determines what kind of test the expression performs on the domain of the input context; for an arbitrary definite determiner DET, a syntactically complex definite of the form 'DET $F$ ' at the very least requires that there be a discourse referent in the domain that satisfies $F$ in some of the world/assignment pairs from the satisfaction set. Second, the predicate plays a role in shaping the resulting satisfaction set; only world/assignment pairs in which the discourse referent in question satisfies $F$ survive.

Now, consider the problematic Wolter data again:

(11) \#That current president of the United States is Donald Trump.

(12) The current president of the United States is Donald Trump.

(13) That guy who is currently president of the United States is Donald Trump.

The key claim I have argued for in this paper is that any semantics for complex demonstratives must provide an explanation of why (13), but not (11) — which by everyone's lights should be semantically indiscernible from (13) - admits an interpretation on which it has the same truth conditions as (12) does.

In the case of (11) and (13), what this means is that we need a way of distinguishing either a.) the test realized by a demonstrative formed with 'is a current president of the United States' from the test realized by a demonstrative formed with 'guy who is currently president of the United States' or b.) updates involving demonstratives formed from the two predicates. Unless we are willing to radically revise our analysis of the structure of the restrictive relative clause, however, there will be no way to distinguish these things. Modulo an irrelevant difference in the gender features associated with 'guy', every object that satisfies 'current president of the United States' will satisfy 'is a guy who is currently president of the United States' ${ }^{29}$ So, any Heim context that supports an update using the former will support an update using the latter, and the updates sentences involving the two demonstratives realize will be indiscernible (again, holding in abeyance differences involving the gender presupposition introduced by the presence of 'guy').

The upshot is that the problem posed by sentences like our (11)-(13) transcends the static/dynamic distinction, and transcends any particular way of implementing either of the pictures. I have suggested that the difference between the felicitous and the infelicitous versions of the demonstrative might be explained by means of a combination of uniqueness and anti-uniqueness presuppositions. That strategy could be realized

\footnotetext{
28 Although note that Rothschild (2011), Yalcin (2012, 2013), Yalcin and Rothschild (2016), and others have shown how many of the features that are standardly associated with dynamic semantic systems can be modeled in a static system, and vice-versa.

29 As observed in note 11, although the result sounds wooden, 'that person who is currently president of the United States' or 'that individual who...' could be used to make the same point as (11).
} 
in a Roberts-style dynamic system, or in dynamic systems like the one described by Zeevat (1999), or in any other dynamic system — but only if the syntax allowed us to treat 'guy' and 'who is currently president of the United States' as realizing distinct tests on the input context. I can imagine someone else eschewing my suggested strategy in favor of a strategy invoking the difference between weak and strong familiarity, or by using some of the other resources dynamic semantics makes available, like the machinery that allows a single sentence to involve several successive updates to the context. Neither of those strategies, however, will make any difference if 'current president of the United States' and 'guy who is currently president of the United States' are treated as constituents with the same semantic value.

\section{Cross-Linguistic Data}

In my view, the English facts are compelling enough on their own to rule out any semantics that fails to explain Wolter demonstratives. The judgments they produce are robust, the problem is not limited to any particularly esoteric subset of the inventory of predicates, and the licensing condition at play appears to be structural. If these data do not demand a direct semantic solution, it is hard to see what kind of data would.

The case for the claim that these data demand serious philosophical attention, however, is made substantially stronger by the fact that the phenomenon Wolter discovered is not a phenomenon that is specific to English. Indeed, exactly the same pattern occurs in a wide variety of distantly-related and unrelated languages. This suggests that the phenomenon in question may be the result of a fundamental feature of demonstratives per se. Consider, for example, the following data from Russian:

(41) Avtor romana Idiot rodilsya v Moskve. Author of.novel Idiot was.born in Moscow.

'The author of The Idiot was born in Moscow.'

As (41) shows, Russian has no overt equivalent of the non-demonstrative English definite article; definite descriptions are formed using bare nouns. Like English, however, Russian does have overt demonstrative determiners. And like in English, those determiners can be used to produce complex demonstratives that are interpreted just like definite descriptions. So, for example, the complex demonstrative from (42) is equivalent to the definite description from $(41)^{30}$ :

(42) Etot pisatel', kotoryi napisal roman Idiot, rodilsya v Moskve. That author, who wrote novel Idiot, was.born in Moscow.

'That author who wrote The Idiot was born in Moscow.'

\footnotetext{
${ }^{30}$ It is important to be clear that it is a Russian orthographic convention to set all relative clauses off with commas. So, the presence of commas in (42) should not be taken to suggest that the relative clause is interpreted non-restrictively. Indeed, it should be clear that a non-restrictive reading of the clause would not deliver determinate truth conditions.
} 
As in English, however, not every demonstrative construction has a non-deictic interpretation. ${ }^{31}$ If we replace the relative clause construction from (42) with a relational genitive like 'author of', the result is infelicitous:

(43) \#Etot avtor romana Idiot rodilsya v Moskve.

That author of.novel Idiot was.born in Moscow.

'\#That author of The Idiot was born in Moscow.'

This, of course, is exactly the pattern we see with Wolter demonstratives in English. Importantly, English and Russian are not unique in this regard. Consider the following data from Spanish:

(44) El autor que escribió el Quijote nació en Alcalá de Henares. The author who wrote the Quijote was.born in Alcalá de Henares.

'The author of Quixote was born in Alcalá de Henares.'

The definite description from (44) can be rendered using a demonstrative formed from a relative clause:

(45) Ese autor que escribió el Quijote nació en Alcalá de Henares.

That author who wrote the Quijote was.born in Alcalá de Henares.

'The author of Quixote was born in Alcalá de Henares.'

But replacing the relative clause construction with 'author of' results in a defective string: 32

(46) \#Ese autor del Quijote nació en Alcalá de Henares.

That author of.the Quixote was.born in Alcalá de Henares.

'\#That author of Quixote was born in Alcalá de Henares.'

The facts about Korean, a language that is generally assumed to be a language isolate, are subtler, but still suggest a pattern similar to the one we have observed in English, Russian, and Spanish. Native speaker informants report that the following sentences are totally natural, and that the demonstratives are interpreted in the way English definite descriptions would be:

(47) Waverley-rul ssu-n gu ja-nun Scott-i-ot-da.

Waverley-ACC write-EMBED that guy-NOM Scott-be-PAST- DECL

'That guy who wrote Waverley was Scott.'

(48) Waverley-rul ssu-n gu ja-nun ttohan Ivanhoe-rul

Waverley-ACC write-EMBED that guy-NOM also Ivanhoe-ACC

ssu-ot-da.

write-PAST-DECL

'That guy who wrote Waverley also wrote Ivanhoe.'

\footnotetext{
31 The informants who provide these data note that if we imagine that The Idiot had two authors, the demonstrative in question could be used deictically to pick out one of them.

32 The native speaker informant who provided these data and commentary on them suggests, without prompting, that the problem has to do with some implication that there were two authors of Quijote. If we assume there were two authors, we can imagine a felicitous deictic use, according to the informant.
} 
The same informants report that while the following variations on (47) and (48) are acceptable, they sound 'way weirder':

(49) ?Waverley-ui gu jakga-nun Scott-i-ot-da.

Waverley-GEN that author-NOM Scott-be-PAST- DECL

'?That author of Waverley was Scott.'

(50) ?Waverley-ui gu jakga-nun ttohan Ivanhoe-rul ssu-ot-da.

Waverley-GEN that author-NOM also Ivanhoe-ACC write-PAST-DECL

'?That author of Waverley also wrote Ivanhoe.'

One informant offers the following explanation of a hypothetical context that would license (49) and (50):

[Here], it sounds like the speaker had said a bunch of things about Scott before uttering (49)/(50). It sounds as if he finally reveals the name of the person he has been talking about. (p.c.)

Although a proper investigation of the Korean data would require a paper of its own, the implication here is that to the extent that (49) and (50) are acceptable, they are acceptable because an anaphoric use is imaginable. The contrast with (47) and (48), which do not impose this interpretive shading, remains.

Finally, although I have been unable to test the relative clause/relational genitive contrast in Mandarin myself, published work on the language makes a related point that bears directly on the question we are concerned with. Huang (1982) credits Chao (1968) with being the first to notice a structurally-induced contrast in the interpretations that are available for complex demonstratives. ${ }^{33}$ Consider:

(51) neiben wo zuotian mai de shu that I yesterday buy DE book

'That book, which I bought yesterday'

(52) wo zuotian mai de neiben shu

I yesterday buy DE that book

'The book that I bought yesterday'

(53) na-yi-ge [chouyan de] ren

that-one-CL smoke DE person

'That person, who smokes'

(54) [chouyan de] na-yi-ge ren

smoke DE that-one-CL person

'The person that smokes'

\footnotetext{
33 I am indebted to Peter Jenks for bringing the literature on Mandarin demonstratives to my attention and to Peter Jenks for further helpful discussion. Examples (51) and (52) are from Huang (1982). Examples (53) and (54) are from del Gobbo (2003). I modify Del Gobbo's gloss of (53) to make it parallel Huang's gloss for (51), and thus to reveal more clearly the intended deictic interpretation. Del Gobbo uses the abbreviation 'CL' to indicate a classifier, and 'DE' the word 'de', which is a modification marker.
} 
Lin (2003) describes a broad agreement among authors about the fact that the syntactic configuration from (51) and (53) systematically produces deictic interpretations, while the interpretations associated with (52) and (54) are non-deictic.

This is especially interesting for our purposes because the word order in Mandarin reveals that in the case of the non-deictic demonstratives, the noun and the relative clause that we would expect to modify it do not combine to form a constituent. Lin (2003) and del Gobbo (2003) analyze Huang's demonstrative-initial constructions using the following structure:

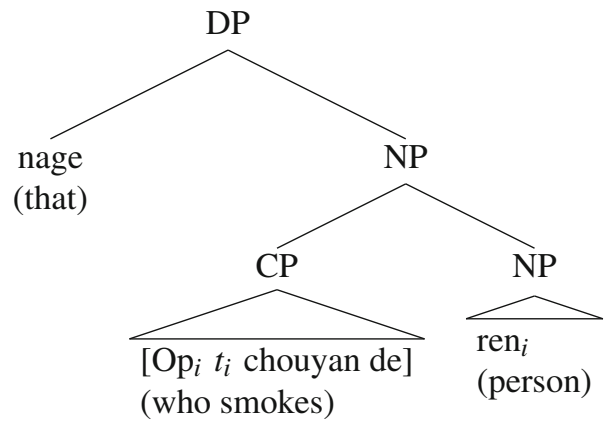

In the relative clause-initial constructions, on the other hand, they claim that the demonstrative combines first with an unmodified NP and later with the relative clause:

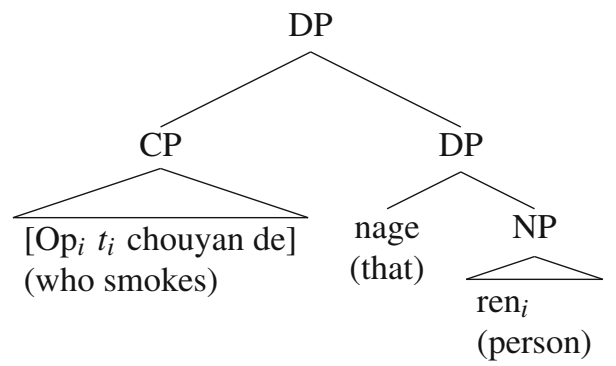

The Mandarin data show, in other words, that when a noun combines with a relative clause to form a single constituent, the resulting demonstrative must be interpreted deictically. This is exactly what we saw in English; recall that we allowed that demonstratives like 'that current president of the United States' would be felicitous in a counterfactual context in which there were two current presidents, and the speaker used the demonstrative while pointing at one.

When a noun and a relative clause occur together in a demonstrative without forming a constituent, on the other hand, the result in Mandarin is a non-deictic interpretation. This construction has no analogue in English. The hypothetical solution to our problem, however- the one that depended on the determiner's being able to test the semantic properties of the noun and the relative clause separately-was precisely a solution that would depend on the availability of a structure like this one. So, at the very least, the Mandarin data suggest that the kind of structural licensing that English appears to involve is manifest in at least some languages.

Of course, the Mandarin non-deictic data raise significant questions of their own. Philosophers who are committed to the idea that semantic composition proceeds 
locally will wonder: how could the derivation for (56) possibly proceed? And why should a structure like (55) produce only a deictic interpretation, while structure (56) only a non-deictic one? While answering these questions in detail would go well beyond the scope of our remit here, it is interesting to note that both Lin and Del Gobbo answer both questions at once by employing a piece of machinery Bach and Cooper (1978) used to avoid a challenge from Partee (1975) about the compositionality of a similar structure from Hittite. Lin writes:

Context-dependency [ed: of deictic demonstratives] can be nicely captured by introducing to the usual translations of determiners an extra property variable whose value is filled by a variable assignment. However, if there is overt linguistic material denoting a property around the property variable, the variable can be filled by that property...(2003, p. 230)

In other words, Lin and del Gobbo treat the Mandarin demonstrative determiner in roughly the same way as our hidden argument theorist treated 'that', claiming that it performs a semantic operation not on one property, but two. ${ }^{34}$ If (55) provides the right structure for (53), then when the noun and the relative clause form a constituent, they jointly occupy only one of the two argument places introduced by the demonstrative determiner, making the second available for contextual saturation. On the other hand, when the structure of the demonstrative expression allows 'overt linguistic material' (here in the form of a high relative clause) to supply a distinct property-type argument, there is no work left for the context to do, and the expected interpretation turns out like a definite description. ${ }^{35}$

The upshot for us is that Mandarin demonstrative constructions involving relative clauses provide yet another reason for thinking that the kinds of issues we have grappled with in confronting Wolter demonstratives are issues that are cross-linguistically general. ${ }^{36}$ Philosophers tempted to defend HOMOPHONY or HIDDEN ARGUMENTS by writing the Wolter data off as marginal must take this fact seriously.

\section{Conclusion}

The point I have argued for in this paper is an entirely negative one. Although it may sound strange, however, my hope is that the real significance of the paper will be positive. Linguists and philosophers have done undeniably excellent work categorizing and characterizing a vast range of uses of complex demonstratives, involving examples of all of the sorts with which I began, and many more besides. Practitioners from both fields have used subtle patterns in the data to produce generations of successively

\footnotetext{
34 Lin (2003) endorses a Fregean semantics on which the determiner takes two arguments and returns their unique joint satisfier, while del Gobbo (2003) treats the determiner in quantificational terms, in roughly the way King (2001) does.

35 Compare the discussion from note 19.

36 They also, of course, provide a possible model for a positive solution to the problem of the English data. We could follow Matthewson (1999), who uses data involving quantification in Salish to argue for a radical proposal about quantification in English, and take the Mandarin data to provide an argument against STANDARD SYNTAX.
} 
more refined theories, and we are surely in a better place now than we were at the beginning of the research project. Nevertheless, if the arguments I have given here are successful, there is a limit to how far we will be able to get by iterating the basic theoretical frameworks that have been settled upon so far. I suspect that the recent equilibrium state that appears to have been achieved in the philosophical literature on complex demonstratives - with most recent contributions turning away from semantic questions towards questions posed at the level of metasemantics - is the result not of our having solved all the interesting semantic problems, but of our having reached that limit. The time has come for us to openly acknowledge the challenge I describe here, and to have a frank discussion about what meeting that challenge will entail. With a bit of luck, that discussion may shake up the terrain in a way that allows us to move forward.

Funding This work was partially supported by the Leverhulme Trust, grant ECF-2019-608.

Open Access This article is licensed under a Creative Commons Attribution 4.0 International License, which permits use, sharing, adaptation, distribution and reproduction in any medium or format, as long as you give appropriate credit to the original author(s) and the source, provide a link to the Creative Commons licence, and indicate if changes were made. The images or other third party material in this article are included in the article's Creative Commons licence, unless indicated otherwise in a credit line to the material. If material is not included in the article's Creative Commons licence and your intended use is not permitted by statutory regulation or exceeds the permitted use, you will need to obtain permission directly from the copyright holder. To view a copy of this licence, visit http://creativecommons.org/licenses/by/4.0/.

\section{References}

Bach, E., \& Cooper, R. (1978). The NP-S analysis of relative clauses and compositional semantics. Linguistics and Philosophy, 2(1), 145-150.

Braun, D. (2008). Complex demonstratives and their singular contents. Linguistics and Philosophy, 31, 57-99.

Chao, Y. R. (1968). A grammar of spoken Chinese. California: University of California Press.

Comorovski, I. (2007). Constituent questions and the copula of specification. In I. Comorovski \& K. von Heusinger (Eds.), Existence: Semantics and syntax (pp. 49-78). Berlin: Springer.

Cooper, R. (1975). Montague's semantic theory and transformational syntax. PhD thesis, University of Massachussetts.

Corrazza, E. (2003). Complex demonstratives qua singular terms. Erkenntnis, 59, 263-283.

Davies, M. (1982). Individuation and the semantics of demonstratives. Journal of Philosophical Logic, 11, 287-310.

de Vries, M. (2006). The syntax of appositive relativization: On specifying coordination, false free relatives, and promotion. Linguistic Inquiry, 37(2), 229-270.

del Gobbo, F. (2003). Appositives at the interface. PhD thesis, University of California at Irvine.

Dever, J. (2001). Complex demonstratives. Linguistics and Philosophy, 24(3), 271-330.

Elbourne, P. (2005). Situations and individuals. Cambridge: MIT Press.

Georgi, G. (2012). Reference and ambiguity in complex demonstratives. In W. P. Kabasenche, M. O'Rourke, \& M. H. Slater (Eds.), Reference and referring (pp. 357-384). Cambridge: MIT Press.

Heim, I. (1982). The semantics of definite and indefinite noun phrases. PhD thesis, University of Massachussetts, Amherst.

Heim, I., \& Kratzer, A. (1998). Semantics in generative grammar. Oxford: Blackwell.

Higgins, F. R. (1979). The pseudo-cleft construction in English. New York: Garland Publishing.

Huang, C.-T. J. (1982). Logical relations in Chinese and the theory of grammar. PhD thesis, MIT.

Kaplan, D. (1977). Demonstratives. In J. Almog, J. Perry, \& H. Wettstein (Eds.), Themes from Kaplan (pp. 481-563). Oxford: Oxford University Press. 
Karttunen, L. (1976). Discourse referents. In J. McCawley (Ed.), Syntax and semantics (Vol. 7). New York: Academic Press.

Kayne, R. S. (1994). The antisymmetry of syntax. Cambridge: MIT Press.

King, J. C. (1999). Are complex 'that' phrases devices of direct reference? Noûs, 33(2), 155-182.

King, J . C. (2001). Complex demonstratives: A quantificational account. Cambridge: MIT Press.

King, J. C. (2008). Complex demonstratives, QI uses, and direct reference. Philosophical Review, 117(1), 99-117.

Lakoff, R. (1974). Remarks on 'this' and 'that'. Proceedings of the Chicago Linguistics Society, 10, 345356.

Lin, J.-W. (2003). On restrictive and non-restrictive relative clauses in Mandarin Chinese. The Tsing Hua Journal of Chinese Studies, 33(1), 199-240.

Maclaran, R. (1982). The semantics and pragmatics of English demonstratives. PhD thesis, Cornell University.

Matthewson, L. (1999). Quantification and the nature of cross-linguistic variation. Natural Language Semantics, 9, 145-189.

Mikkelsen, L. (2005). Copular Clauses: Specification, Predication, and Equation. Amsterdam: John Benjamins.

Neale, S. (1993). Term limits. Philosophical Perspectives, 7, 89-123.

Nowak, E. (2019). Complex demonstratives, hidden arguments, and presupposition. Synthese, https://doi. org/10.1007/s11229-019-02250-5.

Nunberg, G. D. (1993). Indexicality and deixis. Linguistics and Philosophy, 16, 1-43.

Partee, B. (1975). Montague grammar and transformational grammar. Linguistic Inquiry, 6(2), 203-300.

Potts, C., \& Schwarz, F. (2010). Affective 'this'. Linguistic Issues in Language Technology-LiLT, 4(5), 1-30.

Quine, W. (1960). Word and Object. : MIT Press.

Reimer, M. (1991). Demonstratives, demonstrations, and demonstrata. Philosophical Studies, 63, 187-202.

Roberts, C. (1987). Modal subordination, anaphora, and distributivity. PhD thesis, University of Massachussetts.

Roberts, C. (2002). Demonstratives as definites. In K. van Deemter \& R. Kibble (Eds.), Information sharing. Stanford: CSLI.

Roberts, C. (2003). Uniqueness in definite noun phrases. Linguistics and Philosophy, 26, 287-350.

Rothschild, D. (2011). Explaining presupposition projection with dynamic semantics. Semantics and Pragmatics, 4(3), 1-43.

Rothschild, D. (2018). Dynamics of conversation. danielrothschild.com/dyncon.

Salmon, N. (2002). Demonstrating and necessity. Philosophical Review, 111(4), 497-537.

Salmon, N. (2006). Terms in bondage. Philosophical Issues, 16, 263-274.

Salmon, N. (2008). That F. Philosophical Issues, 141, 263-280.

Sauerland, U. (2003). Unpronounced heads in relative clauses. In K. Schwabe \& S. Winkler (Eds.), The interfaces: Deriving and interpreting omitted structures (pp. 205-226). Amsterdam: John Benjamins.

Stockwell, R. P., Schachter, P., \& Partee, B. (1973). The major syntactic structures of English. Rinehart and Winston, New York: Holt.

Vendler, Z. (1967). Linguistics in philosophy. New York: Cornell University Press.

Wolter, L. (2006). That's that; the semantics and pragmatics of demonstrative noun phrases. PhD thesis, University of California at Santa Cruz.

Wolter, L. (2007). Situation variables and licensing by modification in opaque demonstratives. Proceedings of Sinn und Bedeutung, 11, 612-625.

Wolter, L. (2009). Demonstratives in philosophy and linguistics. Philosophy Compass, 4, 451-468.

Yalcin, S. (2012). Introductory notes on dynamic semantics. In G. Russell \& D. G. Fara (Eds.), Routledge companion to the philosophy of language (pp. 253-279). Abingdon: Routledge.

Yalcin, S. (2013). Introductory notes on dynamic semantics. Manuscript to supersede 2012 with same title. Yalcin, S., \& Rothschild, D. (2016). Three notions of dynamicness in language. Linguistics and Philosophy, 39(4), 333-355.

Zeevat, H. (1999). Demonstratives in discourse. Journal of Semantics, 16(4), 279-313.

Publisher's Note Springer Nature remains neutral with regard to jurisdictional claims in published maps and institutional affiliations. 